\title{
O DEPÓSITO A PRAZO COM GARANTIA ESPECIAL E O RISCO MORAL NOS BANCOS BRASILEIROS: UMA ANÁLISE EMPÍRICA COM DADOS DE PAINEL
}

\author{
THE TIME DEPOSIT WITH SPECIAL GUARANTEE AND MORAL HAZARD IN \\ BRAZILIAN BANKS: AN EMPIRICAL ANALYSIS WITH PANEL DATA
}

Rafael Machado Santana

Universidade de Brasília (UnB) e Banco Central do Brasil (BCB), Brasilia, DF, Brasil. As opiniões expressas neste trabalho são exclusivamente dos autores e não refletem, necessariamente, a visão do Banco Central do Brasil. E-mail: rafael.m.santana@gmail.com.

José Luís Oreiro

Universidade de Brasília (UnB), Brasília, DF, Brasil. E-mail: joreirocosta@yahoo.com.br.

Recebido em: 12.01.2017 - Aceito em: 10.02.2017

\section{RESUMO}

O depósito a prazo com garantia especial (DPGE) do Fundo Garantidor de Crédito (FGC), criado em março de 2009 como resposta aos impactos da crise financeira internacional sobre o Brasil, conseguiu restabelecer a liquidez dos bancos de menor porte ao definir que as captações feitas por meio desse instrumento fossem garantidas até o total de $\mathrm{R} \$ 20$ milhões por depositante e por instituição financeira. Muito embora a medida tenha tido êxito em aliviar as restrições de liquidez dos bancos de menor porte, ela pode ter causado, como efeito colateral, um risco maior de insolvência dessas instituições em função do risco moral resultante do seguro depósito presente no DPGE. Em função disso, este trabalho investiga, a partir de dados em painel, se os bancos de menor porte passaram a assumir maiores riscos após a criação do DPGE. Como grupos de controle da análise são utilizados os bancos de maior porte, para os quais o DPGE foi uma medida inócua, e as cooperativas de crédito, onde a captação através do DPGE não esteve disponível. Os resultados não mostram evidências de que houve um aumento dos riscos assumidos pelos bancos de menor porte após a criação do DPGE.

Palavras-chave: risco moral, seguro depósito, dados em painel, Arellano e Bond

\section{ABSTRACT}

The time deposit with special assurance (DPGE) from the Credit Insurance Fund (FGC), established in March 2009 amid the effects of the global financial crisis on Brazil, reestablished the access of local currency funding for smaller banks 
putting in place a deposit insurance for DPGE reaching up to $R \$ 20$ million per depositor in each bank. Although successful in managing the liquidity difficulties of smaller banks, the DPGE might have increased the risk of insolvency of those banks because of the moral hazard associated with the deposit insurance. Therefore, this paper uses panel data to investigate if smaller banks were engaged in riskier operations after the creation of DPGE. As control groups for our analysis we use larger banks, for which DPGE did not represented a viable source of funding, and credit unions, which were not allowed to fund themselves through DPGE. Our estimates do not show evidences that smaller banks were engaged in riskier operations after the establishment of DPGE.

Keywords: moral hazard, deposit insurance, panel data, Arellano and Bond Classificação JEL: E58; G21; G28.

\section{INTRODUÇÃO}

No ápice da crise financeira internacional, com a quebra do banco de investimentos Lehman Brothers, em setembro de 2008, o sistema bancário brasileiro presenciou um movimento de "fuga pela segurança" onde os investidores deslocaram seus recursos para operações garantidas pelo governo federal em detrimento das aplicações em títulos privados, como explicam Mesquita e Torós (2010). Ainda segundo os autores, esse movimento foi particularmente relevante para os bancos de menor porte ${ }^{1}$, uma vez que eles são muito dependentes das captações por depósitos a prazo obtidos junto a um número limitado de investidores institucionais ${ }^{2}$, diferentemente dos bancos maiores que obtêm parte importante de seus recursos através de depósitos à vista, pulverizados. Essa concentração das fontes de recursos dos bancos de menor porte durante o movimento de "fuga pela segurança" fez com que essas instituições sofressem com a falta de liquidez em moeda nacional. A figura 1 mostra como estoque de depósitos a prazo das instituições de menor porte (destacando-se os segmentos pequeno e micro) caiu ao longo do segundo semestre de 2008 e primeiro semestre de 2009. Ademais, nota-se no gráfico o 1 A segmentação pelo porte dos bancos segue o critério do Banco Central do Brasil publicado em seu Relatório de Estabilidade Financeira de abril de 2010 (Brasil, 2010, pg. 81). A partir desse critério, os bancos são classificados em ordem decrescente de participação que cada um tem nos ativos totais do sistema bancário, excluindo-se dessa classificação os bancos que possuem pelo menos 15\% de participação, os quais são classificados diretamente como de grande porte. Em seguida, a partir daquele ordenamento, juntam-se ao segmento dos bancos de grande porte aqueles que compõem a faixa percentual de $0 \%$ a $75 \%$, inclusive, de participação acumulada nos ativos totais do sistema bancário. Por sua vez, os bancos presentes na faixa de $75 \%$ a $90 \%$, inclusive, de participação acumulada são definidos como de médio porte e os bancos na faixa de $90 \%$ a $99 \%$, inclusive, representam os de pequeno porte. Finalmente, os bancos da faixa entre $99 \%$ e $100 \%$ são os bancos de porte micro.

2 Investidores institucionais são compostos por uma gama variada de agentes dos quais podemos citar fundos de pensão, operadoras de planos de saúde, seguradoras, fundações, entre outros. 
movimento destacado por Toledo (2010) de "migração dos depósitos do sistema bancário em direção aos grandes bancos (isto é, um movimento de passivos dentro do sistema)" (pg. 227). Esse ponto se explica pela percepção dos depositantes de que eventuais intervenções do governo, no sentido de garantir a solvência das instituições financeiras, seriam mais prováveis nos bancos de grande porte (to big to fail banks), o que tornaria esses bancos mais seguros durante a crise ${ }^{3}$.

Figura 1 - Variação dos estoques de depósitos a prazo agrupados pelos portes dos bancos (fonte: Relatório de Estabilidade Financeira do Banco Central do Brasil, abril de 2010).

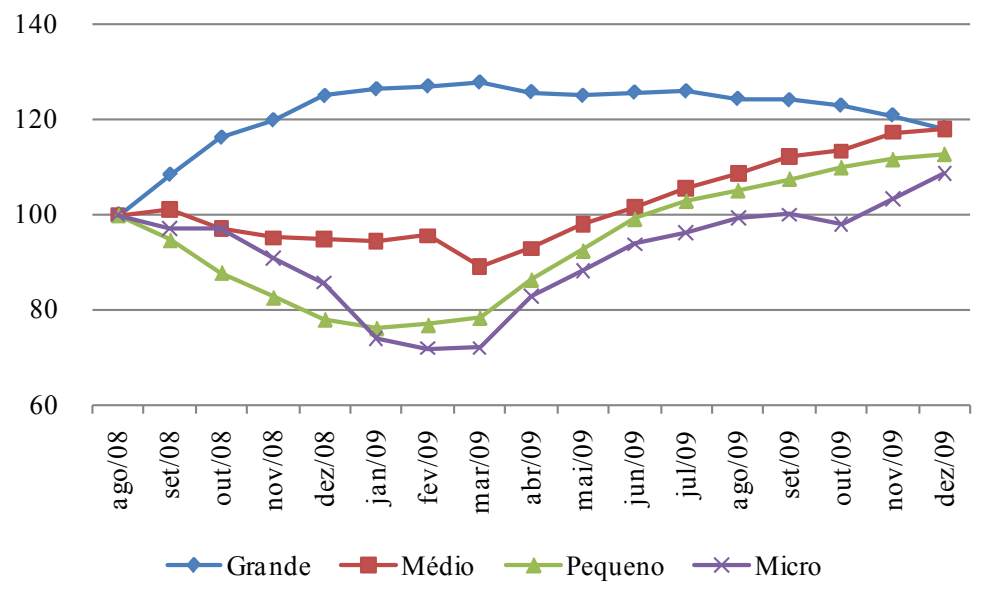

Em função dessa dificuldade de liquidez dos bancos de menor porte ${ }^{4}$, o Conselho Monetário Nacional (CMN) instituiu o depósito a prazo com garantia especial (DPGE) ao final de março de 20095, autorizando o Fundo Garantidor de Crédito (FGC), instituição privada sem fins lucrativos responsável por garantir créditos contra instituições financeiras, a assegurar os depósitos a prazo especiais até o limite de $\mathrm{R} \$ 20$ milhões por pessoa física ou jurídica e por instituição. Até a adoção dessa medida, a garantia oferecida pelo FGC era de no máximo de $\mathrm{R} \$ 60$ mil $^{6}$ para um conjunto de créditos detidos por pessoa contra determinada instituição, do qual faziam parte os depósitos a prazo convencionais. O objetivo da medida era reduzir o risco dos investidores que aplicavam em títulos do sistema bancário, sobretudo naqueles emitidos pelos bancos de menor porte, de modo a restabelecer a liquidez dos bancos ${ }^{7}$.

3 Sobre essa argumentação ver o trabalho de Oliveira, Shiozer e Barros (2011).

4 Vide Toledo (2010), pg. 227, sobre a dificuldade desses bancos em obter liquidez também através da cessão de créditos. 5 Resolução do CMN no 3.692, de 26 de março de 2009, com efeitos a partir de abril de 2009.

6 Ao final de 2010 o valor dos créditos garantidos subiu para $R \$ 70$ mil, de acordo com a Resolução do $C M N n^{\circ}$ 3.931, de 3 de dezembro de 2010. Posteriormente, em maio de 2013, esse valor foi majorado novamente, para $\mathrm{R} \$ 250$ mil, conforme Resolução $\mathrm{CMN} \mathrm{n}^{\circ}$ 4.222, de 23 de maio de 2013.

7 Vide Relatório de Estabilidade Financeira do Banco Central do Brasil, pg. 10, v. 8, n. 2, de outubro de 2009. 
O volume de emissão de DPGE permitido a cada banco recebeu um limite baseado no patrimônio de referência e nos saldos de depósitos a prazo e obrigações por letras de câmbio da instituição, mas com um teto de $\mathrm{R} \$ 5$ bilhões. Ademais, uma vez que se tratava de uma medida emergencial, definiu-se um cronograma de redução desse limite de emissão da seguinte forma: $20 \%$, a partir de $1^{\circ}$ de janeiro de 2012; 40\%, a partir de $1^{\circ}$ de janeiro de $2013 ; 60 \%$, a partir de $1^{\circ}$ de janeiro de 2014 ; $80 \%$, a partir de $1^{\circ}$ de janeiro de 2015 ; e $100 \%$, a partir de $1^{\circ}$ de janeiro de 2016 .

A emissão do DPGE, assim como ocorria com os depósitos a prazos sem a garantia especial, sujeitava a instituição emissora a realizar uma contribuição ao FGC como prêmio pelo seguro prestado pelo fundo. No caso do DPGE, essa taxa foi fixada em $0,0833 \%$ ao mês sobre o saldo dos depósitos ${ }^{8}$.

Com a criação do DPGE, o CMN conseguiu trazer segurança para os aplicadores e restabelecer o nível de liquidez dos bancos de menor porte ${ }^{9}$. Como mencionado anteriormente, até a criação desse depósito especial, o seguro prestado pelo FGC cobria créditos contra instituições financeiras até o limite de $\mathrm{R} \$ 60$ mil por pessoa (física ou jurídica) e por instituição. Isso significava que grandes depositantes, como os investidores institucionais e empresas não-financeiras ficavam praticamente sem cobertura, uma vez que o volume dos seus depósitos superava em muito o limite da garantia do FGC. Por isso, ao criar uma categoria de depósito com garantia de crédito até o valor de $\mathrm{R} \$ 20$ milhões, o CMN conseguiu que os grandes depositantes voltassem a aplicar em instituições de menor porte. De fato, com base em informações do $\mathrm{FGC}^{10}$, o estoque de DPGE emitido entre abril e dezembro de 2009 (primeiro ano de vigência desse instrumento de captação) foi de $\mathrm{R} \$ 14,3$ bilhões. Por sua vez, considerando a variação do saldo de depósitos a prazo dos bancos de menor porte (incluindo os depósitos usuais e os DPGE's) o valor foi de $\mathrm{R} \$ 25,4$ bilhões ${ }^{11}$. Assim, assumindo que o DPGE foi utilizado exclusivamente pelos bancos de menor porte (um pressuposto de discutiremos em mais detalhes abaixo), as captações feitas por esses bancos através desse novo instrumento representaram mais da metade dos recursos obtidos com depósitos a prazo.

8 Caso a instituição ultrapassasse seu limite de emissão de DPGE, o FGC estava autorizado pelo CMN a cobrar dez vezes a taxa normal do depósito, isto é, 0,8333\% a.m., sobre o valor excedente. Para os demais créditos assegurados pelo FGC, mas sem a garantia especial, o valor de contribuição era de 0,025\% a.m. (conforme Resolução do $C M N n^{\circ} 3.251$ de 16 de dezembro de 2004), reduzido posteriormente para $0,0125 \%$ a.m. pela Resolução $\mathrm{CMN}$ n$^{\circ} 4.087$ de 24 de maio de 2012.

9 Vide Relatório de Estabilidade Financeira do Banco Central do Brasil, pg. 44, v. 8, no 2, de outubro de 2009. Antes da criação do DPGE, mas ainda em 2008, o Banco Central do Brasil buscou ampliar a liquidez do Sistema Financeiro Nacional com a liberação dos depósitos compulsórios, mas essa medida não melhorou a situação dos bancos de menor porte porque os recursos não eram emprestados entre os bancos. Pode-se argumentar que as mesmas dúvidas dos aplicadores com relação à solvência desses bancos também existiu entre os bancos com seus pares, de modo a dificultar os empréstimos de reservas no sistema.

10 Relatório anual da administração, disponível em www.fgc.org.br (acesso em 31/03/2013).

11 Valor obtido a partir dos balancetes dos bancos, disponíveis no sítio do Banco Central do Brasil na internet, www.bcb.gov.br (acesso em 31/03/2013). 
A despeito do sucesso do DPGE em restabelecer o acesso à liquidez dos bancos menores e, nesse sentido, ter sido uma medida positiva para a estabilidade do Sistema Financeiro Nacional, uma importante questão não foi considerada sobre o efeito do DPGE no médio e longo prazo: o risco moral induzido pelo seguro oferecido no DPGE.

O risco moral diz respeito a uma situação onde um agente toma a decisão sobre assumir determinado risco, mas onde as perdas associadas a esse risco, se ocorrerem, recaem sobre outro agente. O exemplo tradicional dado para descrever o risco moral se baseia no mercado de seguros de automóveis. O proprietário de um carro, após contratar um seguro contra roubo, tende a ser menos precavido em evitar o roubo do veículo do que seria caso não tivesse o seguro, pois sabe que se eventualmente roubarem seu carro a perda será coberta pela seguradora.

No caso do DPGE, o problema do risco moral é um exemplo recente de um problema identificado na literatura de microeconomia bancária quando existe a figura do seguro depósito e o prêmio desse seguro não é sensível ao risco de insolvência da instituição coberta pelo seguro (MARCUS, 1984) ${ }^{12}$.Outra forma de evidenciar o risco moral no seguro depósito está em que o banco, ao captar através de um depósito que protege o credor do risco de crédito, paga pelos recursos obtidos um valor próximo ao dos juros livre de risco. Por sua vez, o banco pode aplicar esses recursos em operações mais arriscadas e de maior retorno ganhando a diferença entre as taxas de juros, já compensada pelas perdas das operações ativas. Note que, do ponto de vista do depositante, não importa o quão arriscado são as operações ativas do banco e, por isso, o custo de captação da instituição continua próximo à taxa livre de risco. O risco moral se evidencia aqui se considerarmos o que aconteceria se não houvesse o seguro sobre os depósitos. Nesta situação os credores levariam em conta o perfil de risco do banco e exigiriam uma remuneração alinhada com esse perfil, o que, por sua vez, limitaria o apetite a risco do banco. $\mathrm{Na}$ ausência do seguro, quanto mais arriscadas forem as aplicações do banco, maior será seu custo de financiamento, e isto tende a reduzir, e até eliminar, o ganho de se assumir maiores riscos.

No entanto, existem mitigadores do efeito do seguro depósito sobre o risco moral. Como argumentam Gueyie e Lai (2003), fatores como a regulação bancária $^{13}$, a disciplina de mercado e a própria aversão a risco do banco podem limitar a tomada excessiva de risco da instituição. Como exemplo de regulação, os bancos podem sofrer restrições sobre as operações ativas originadas com recursos dos depósitos a prazo. É o caso dos recolhimentos compulsórios impostos aos ban-

12 Vide Merton (1977) e Chan et al. (1992).

13 A respeito do papel da regulação em limitar o risco moral vide Buser et al. (1981), McCulloch (1986) e Freeman (1988). 
cos sobre parte dos depósitos, por onde o risco das operações ativas é limitado porque os recolhimentos são feitos em ativos de baixo risco. Outro mitigador é exigência de níveis mínimos de capital que as instituições devem ter para operar. Quanto maior for a participação do capital próprio de um banco no financiamento de seus ativos, menor é a importância do risco moral associada ao seguro depósito, uma vez que este risco pressupõe a utilização de recursos de terceiros ${ }^{14}$. Assim, não se pode afirmar, a priori, que o seguro depósito cria um problema de risco moral nos bancos sem considerar outros fatores que limitam a exposição de risco dessas instituições.

Com base no que foi exposto, este artigo se propõe a verificar empiricamente se a criação do DPGE não incentivou os bancos a realizar operações ativas mais arriscadas do que as que seriam feitas se os custos de captação dessas instituições refletissem os riscos por elas assumidos.

É importante destacar que ao restabelecer o acesso à liquidez em moeda local dos bancos de menor porte, o DPGE pode ter possibilitado a continuidade das operações de crédito nesses bancos. Dessa forma, pode-se se esperar que 0 risco do banco, medido em termos absolutos, tenha aumentado após a criação do depósito especial. No entanto, o que pretendemos investigar aqui é se o risco aumentou além do que seria esperado em uma situação sem a existência do DPGE. Por isso, faremos duas análises econométricas com dados em painel trabalhando com variáveis e grupos de controle para identificar o efeito exclusivo do DPGE.

Em uma primeira análise compararemos os riscos assumidos pelos bancos de menor porte com os riscos assumidos pelos bancos maiores. Como argumentaremos abaixo, para esse segundo grupo de bancos a criação do DPGE foi uma medida inócua, pois ela não influenciou a forma de captação dessas instituições.

Em uma segunda análise, trocaremos os bancos maiores pelas cooperativas singulares de crédito na comparação com os riscos assumidos pelos bancos de menor porte. As cooperativas podem captar recursos por depósitos a prazo, realizam operações de crédito (portanto, assumem riscos) e estão sujeitas aos requerimentos de capital. Dessa forma, possuem alguns atributos semelhantes aos dos bancos. No entanto, às cooperativas não lhes foi permitida a captação via DPGE, o que nos leva a utilizá-las como um grupo de controle e ter uma segunda fonte de comparação para nossos testes.

14 Pode-se observar que outra questão sobre risco moral surge relacionada ao uso capital próprio do banco. Trata-se da relação agente-principal entre os administradores do banco e seus acionistas. No entanto, esse ponto não será discutido aqui, pois nosso foco está no risco moral causado pelo seguro depósito. Ainda assim, essa questão será levada em conta em nossas análises empíricas devido ao método econométrico que empregaremos que assume a existência de efeitos idiossincráticos não-observáveis em cada banco, os quais podem abarcar, entre outros fatores, essa relação agente-principal em determinada instituição. 
Este trabalho está dividido em sete seções, incluindo esta introdução. $\mathrm{Na}$ próxima seção, apresentamos uma revisão bibliográfica dos estudos empíricos que trataram da questão do risco moral associado ao seguro depósito. Em seguida, detalhamos a estratégia empírica empregada para capturar o efeito do DPGE sobre o risco moral, assim como apresentamos a variáveis utilizadas no modelo econométrico. Posteriormente, na seção 4, é feita uma análise descritiva das medidas de risco empregadas. A seção 5 traz os resultados empíricos, enquanto que a seção seguinte faz uma interpretação dos mesmos. Finalmente, a seção 7 conclui o trabalho.

\section{REVISÃO BIBLIOGRÁFICA DOS ESTUDOS EMPÍRICOS SOBRE O RISCO MORAL CAUSADO PELO SEGURO DEPÓSITO}

A ideia de que o seguro depósito induz ao risco moral por parte da instituição receptora dos recursos foi objeto de estudos empíricos do quais podemos destacar o de Grossman (1992). O autor investiga a questão do risco moral em instituições de poupança e empréstimo dos EUA nos anos de 1930 e identifica o surgimento desse risco nas instituições cobertas pelo seguro depósito. Também Brewer e Mondschean (1994), analisando as instituições de poupança e empréstimos dos EUA, mas com dados de 1985 a 1989, encontram "empirical support for the view that the existence of deposit insurance created a moral hazard situation that gave poorly capitalized institutions a greater incentive to increase their risk exposure." (pg. 147). Cabe observar que os autores destacam que o risco moral está inversamente relacionado à capitalização da instituição. A ideia aqui é que bancos mais capitalizados têm mais a perder (capital próprio), caso os riscos dos ativos se materializem.

Mais recentemente, Boyd et al. (2002) apontam a crise bancária na Ásia ao final dos anos 90 como um exemplo prático de risco moral e Demirgüç-Kunt e Huizinga (2004) encontram evidências em dados de diferentes países de que o seguro depósito reduz o custo de captação dos bancos ao mesmo tempo em que aumenta a disposição dessas instituições em assumir riscos. Ainda em relação às evidências internacionais, Barth et al. (2004) também mostram que o seguro depósito aumenta a probabilidade de crises bancárias em diversos países.

Já no sentido de trazer evidências de que existem mitigadores do risco moral e que, portanto, não se consegue identificar o seguro depósito como um fator que aumente a propensão a risco dos bancos temos o trabalho de Santomero e Vinso (1977). Estudando o risco dos bancos nos EUA no período entre 1965 e 1974, os autores mostram que, a despeito do seguro depósito já existir no país no período 
de análise, o risco de quebra dos bancos nos EUA foi muito pequeno. Assim, o trabalho sugere que o seguro depósito, por si só, não foi uma condição suficiente para tornar relevante o risco de quebra dos bancos. Por sua vez, Gropp e Vesala (2004), trabalhando com dados dos bancos da União Europeia no período entre 1992 a 1998, mostram que quando a proteção aos credores do banco fica limitada apenas àqueles detentores de depósitos, deixando de fora credores de outros elementos do passivo, tais como as dívidas subordinadas, o seguro depósito pode diminuir a exposição a risco dos bancos se o seu limite de cobertura for considerado crível. Isto é, se em uma situação de crise não existir a possibilidade da cobertura do seguro ser estendida para os demais credores além dos depositantes. Essa sensibilidade da disposição dos bancos em assumir riscos como função do alcance da cobertura do seguro depósito também é identificada por Angkinand e Wihlborg (2010) na comparação de sistemas bancários e mecanismos de seguro depósito em 52 países no período entre 1997 e 2003.

No Brasil, Bressan et at. (2012) exploram o efeito da cobertura dada pelo Fundo Garantidor do Sicoob ${ }^{15}$ (FGS) aos depósitos feitos em cooperativas de crédito e também rejeitam a hipótese de que o seguro induziu ao risco moral nas cooperativas.

\section{ESTRATÉGIA EMPÍRICA E DESCRIÇÃO DAS VARIÁVEIS}

Nesta seção apresentaremos o modelo econométrico empregado para identificar o efeito do DPGE sobre os riscos assumidos pelos bancos. Ademais, apresentaremos as medidas de risco utilizadas em nossas análises, discutiremos o período em que consideraremos que o DPGE pode ter tido efeito sobre os riscos dos bancos e apresentaremos os grupos e variáveis de controle empregadas para buscar identificar o efeito do DPGE.

\subsection{Modelo de referência}

Para verificar o efeito do DPGE sobre o risco moral nos bancos menores estimaremos um painel com dados semestrais dos seus balancetes e seus índices de Basileia para o período entre junho de 2007 a dezembro de 2010. Também são obtidas essas informações dos bancos de maior porte e das cooperativas singulares de crédito para servir de controles na estimação no modelo, junto com dados macroeconômicos. Uma formulação geral do modelo é dada por:

$$
y_{i t}=\rho y_{i t-1}+X_{i t}^{\prime} \boldsymbol{\beta}+M_{t}^{\prime} \boldsymbol{\gamma}+\alpha d_{t}+\psi D_{i t}+c_{i}+u_{i t}, i=1_{2 \ldots,}, N ; t=1, \ldots, T .
$$

15 Sistema das Cooperativas de Crédito do Brasil. 
onde $i$ denota as instituições da amostra (bancos menores e maiores, ou bancos menores e cooperativas), $t$ é o tempo em semestres, $y_{i t}$ é um escalar mensurando o risco assumido pelo instituição $i$ no instante $t, \rho$ é o coeficiente auto-regressivo que captura a persistência da variável dependente, $X_{i t}=\left[\begin{array}{llll}x_{1, i t} & x_{2, i t} & \ldots & x_{j, i t}\end{array}\right]$ é um vetor com $j$ controles de características observáveis do banco ou cooperativa i no instante $t$, que chamaremos de micro-controles, $M_{t}=\left[m_{1, t} m_{2, t} \ldots m_{k, t}\right]$ é um vetor com $k$ variáveis de controle que afetam igualmente todos os indivíduos da amostra, denominadas macro-controles. $\mathrm{O}$ termo $\alpha$ captura mudanças macroeconômicas que afetem todos os indivíduos ao mesmo tempo e que podem ter ocorrido concomitantemente à criação do DPGE. A variável associada a esse coeficiente, $d_{t}$, é uma dummy que assume valor igual a um a partir da data em que consideramos que o DPGE pode ter afetado os riscos assumidos pelos bancos. Por sua vez, o efeito do DPGE sobre os bancos de menor porte é capturado pelo coeficiente $\psi$, sendo a variável $D_{i t}$ uma dummy semelhante $d_{t}$, que assume valor igual junto com $d_{t}$, mas apenas para os bancos de menor porte. $O$ termo $c_{i}$ representa fatores particulares do banco $i$, invariáveis no tempo e que influenciam o risco assumido. O termo $u_{i t}$ é o choque aleatório do modelo em relação a $y_{i t}$. Por fim, $N$ representa o número de instituições e $T$ o número total de semestres da amostra.

A respeito da variável dependente defasada, o motivo de considerarmos a persistência temporal dos riscos assumidos pelos bancos decorre da forma como esses riscos são medidos. Tanto no caso da mensuração feita através da classificação das operações de crédito, como no caso da utilização do índice de Basileia, o determinante dos riscos de um banco em certo mês são as operações em aberto realizadas por ele até aquele mês. Como em diversos casos essas operações têm prazos de vencimento superiores a um semestre (financiamentos de bens duráveis e de capital, para citar dois exemplos), elas impactam as medidas de risco por diversos períodos, dando-Ihes persistência temporal.

Devido à presença do termo auto-regressivo e do efeito idiossincrático, faremos uso do estimador baseado em Arellano e Bond (1991), que utiliza o método dos momentos generalizados (generalized method of moments), GMM, sendo estimado em dois estágios ${ }^{16}$.

16 Para os testes de significância dos coeficientes do modelo empregamos a correção da variância dos estimadores proposta por Windmeijer (2005) que trata do viés desses estimadores em amostras finitas. 


\subsection{Segmentação dos bancos pelo porte}

Pela figura 1 vemos que os bancos definidos pelo BACEN como de portes médio, pequeno e micro, foram os que apresentaram quedas nos estoques de depósitos a prazo até março de 2009 (com maior intensidade nos bancos pequenos e micros) e recuperação dos saldos a partir de então com a criação do DPGE. Isso sugere que o DPGE tenha sido uma medida efetiva para esses grupos de bancos, o que nos leva a adotar como bancos de menor porte os bancos definidos pelo BACEN como médios, pequenos e micros.

Como a lista de bancos de menor porte somou mais de cem instituições e ficaria muito extensa, apresentamos na tabela abaixo apenas os bancos que consideramos como sendo de grande porte ${ }^{17}$.

Tabela 1 - Bancos de grande porte (data-base de referência, junho de 2009)

\begin{tabular}{lr}
\hline Nome da instituição & Ativo total (R\$ mil) \\
\hline Banco do Brasil & 583.325 .840 \\
Itaú-Unibanco & 576.565 .193 \\
Bradesco & 425.956 .252 \\
Santander & 332.617 .159 \\
Caixa Econômica Federal & 323.656 .801 \\
BNDES & 303.875 .762 \\
HSBC & 106.145 .278 \\
Votorantim & 90.204 .436 \\
\hline Fonte: Banco Central do Brasil
\end{tabular}

\subsection{Mensuração dos riscos incorridos a partir do índice de Basileia}

A primeira medida de risco empregada neste trabalho é o índice de Basileia. Ele foi estabelecido no Brasil em 1994, pelo CMN, através da Resolução n².099, de 17 de agosto de 1994, que incorporou os princípios do Acordo de Basileia de 1988 (BIS, 1988). Seguindo esses princípios, o CMN determinou critérios para medir a adequação do capital dos bancos frente aos riscos assumidos. Em um primeiro momento, o foco do CMN foi mensurar o risco de crédito incorrido pelas instituições financeiras a partir do conceito de ativos ponderados pelo risco, um valor obtido a partir da conversão de todas as operações do ativo da instituição em exposições de risco de crédito. Sobre esse valor era aplicado o fator de oito por cento para se definir o Patrimônio Líquido Exigido (PLE), que deveria ser menor do que o Patrimônio de Líquido Ajustado (PLA), dado pelo saldo da conta de patrimônio líquido acrescido dos saldos das contas de resultado credoras e deduzido dos saldos das contas de

17 Maiores informações sobre o porte das instituições podem ser encontradas no sítio do Banco Central do Brasil na internet, http://www4.bcb.gov.br/top50/port/top50.asp.(acesso em 24 de março de 2013). 
resultado devedoras. Assim, sendo o índice de Basileia a relação entre PLA sobre PLE, o índice mínimo definido pelo regulador à época foi de $8 \%$.

Posteriormente, o CMN promoveu alterações no cálculo do PLE elevando de oito para $11 \%$ o fator aplicado às exposições de risco de crédito ${ }^{18}$. Além disso, entre os anos de 1999 e 2000 foram incorporados ao PLE os riscos de mercado de variação cambial e de taxa de juros. Ademais, o PLA foi substituído pelo conceito de Patrimônio de Referência (PR) e o PLE, pelo Patrimônio de Referência Exigido (PRE).

Mais adiante, a partir do ano de 2004, o regulador inicia a implantação da revisão do Acordo de Basileia, conhecida também como Basileia II ${ }^{19}$. Nessa revisão, foi aprimorada a abordagem existente para o requerimento de capital para os riscos de crédito, de variação cambial e de variação de taxa de juros. Ademais, partir de julho de 2008, passou-se a exigir capital para os riscos de variações nos preços de commodities e de ações. Além disso, criou-se uma exigência de capital para o risco operacional das instituições financeiras.

Pode-se notar que o motivo de utilizarmos o índice de Basileia (IB) como uma medida de risco está em que ele pretende, justamente, mensurar os riscos assumidos pelas instituições financeiras. Na realidade, a mensuração do risco é feita por meio do PRE. No entanto, para existir comparabilidade entre as instituições se utiliza o IB, que é uma relação entre PRE e PR, dada pela seguinte fórmula:

$$
I B=\frac{P R \cdot 100}{P R E / \text { Fator } F},
$$

onde o fator $F$ é igual a $11 \%$ e determina o mínimo que as instituições podem ter do IB.

Como o IB é função do PRE, do PR e do fator $F$, é importante que os critérios que determinam esses elementos tenham se mantido constantes no período de análise deste trabalho para garantir que o comportamento dos IBs dos bancos ao longo do tempo seja devido apenas pelas operações realizadas pelos bancos, e não por mudanças metodológicas que impactem o índice.

No caso do valor mínimo do índice, o fator F, ele sempre esteve em $11 \%$ em nosso período de análise. Porém, tanto no caso do PR, como do PRE, o cálculo desses valores sofreu alterações ao longo do nosso período de análise.

No caso do PR, a alteração metodológica ocorreu em julho de 2007, quando se determinou que fosse deduzido do seu valor o saldo de certos ativos representados por instrumentos de captação emitidos por bancos e demais instituições auto18 Recentemente, no entanto, o CMN determinou uma redução paulatina do índice de Basileia mínimo, trazendo o valor novamente para oito por cento a partir de janeiro de 2019 (vide Resolução CMN n 4193, de 01 de março de 2013). 19 Vide Comunicado BACEN n 12.746, de 09 de dezembro de 2004. 
rizadas a funcionar pelo BACEN (art. $3^{\circ}$ da Resolução $C M N n^{\circ} 3.444$ ). Por sua vez, no caso do PRE, como comentado acima, as alterações metodológicas ocorreram em julho de 2008 com os aprimoramentos e extensões do requerimento de capital.

Em função dessas mudanças, quando nossas análises empíricas utilizarem o IB como medida de risco, trabalharemos com um período de tempo menor do que o empregado com nossa outra medida de risco. Realizaremos a análise com dados a partir de junho de 2008 e adotaremos como proxy para o IB dessa data o valor de julho de 2008.

Além das alterações de julho de 2008, novas mudanças ocorreram no cálculo das exigências de capital a partir daquela data. No entanto, o IB apenas seria afetado por essas mudanças em um período posterior ao da nossa análise.

Devemos destacar, finalmente, que o IB é uma função decrescente do PRE, que mede os riscos das instituições. Dessa forma, trata-se de uma medida inversa de risco. Por isso, quando mencionarmos que determinada variável deve ter efeito, por exemplo, negativo sobre os riscos assumidos pelos bancos, devemos ter em mente que isso significa um efeito positivo sobre o IB.

\subsection{Mensuração dos riscos incorridos a partir da classificação das ope- rações de crédito}

Como segunda medida de risco foi utilizada as operações de crédito realizadas pelas instituições financeiras. Com base na Resolução CMN n 2682, de 21 de dezembro de 1999, os bancos, as cooperativas de crédito e as demais instituições financeiras autorizadas a operar pelo BACEN, devem classificar suas operações de crédito em ordem crescente de risco nos seguintes níveis $A A, A, B, C, D, E, F$, $\mathrm{G}$ e $\mathrm{H}$, levando em conta os seguintes aspectos:

I - em relação ao devedor e seus garantidores:

a) situação econômico-financeira;

b) grau de endividamento;

c) capacidade de geração de resultados;

d) fluxo de caixa;

e) administração e qualidade de controles;

f) pontualidade e atrasos nos pagamentos;

g) contingências;

h) setor de atividade econômica;

i) limite de crédito;

Il - em relação à operação: 
a) natureza e finalidade da transação;

b) características das garantias, particularmente quanto à suficiência e liquidez;

c) valor. (art. $2^{\circ}$, Resolução $n^{\circ} 2682 / 99$ )

Ademais dos aspectos relacionados acima, as classificações também são definidas pelo atraso nos pagamentos de parcela do principal ou dos encargos. De acordo com a norma temos que:

a) atraso entre 15 e 30 dias: risco nível $B$, no mínimo;

b) atraso entre 31 e 60 dias: risco nível $C$, no mínimo;

c) atraso entre 61 e 90 dias: risco nível $D$, no mínimo;

d) atraso entre 91 e 120 dias: risco nível E, no mínimo;

e) atraso entre 121 e 150 dias: risco nível F, no mínimo;

f) atraso entre 151 e 180 dias: risco nível G, no mínimo;

g) atraso superior a 180 dias: risco nível $H$; (art. $4^{\circ}$, inciso I, Resolução n 2682/99)

A partir dessa classificação, uma de nossas medidas de risco será o quociente entre as operações de crédito de maior risco e o total de operações de crédito, sendo que quanto maior seu valor, maior o risco. Mais especificamente, consideraremos as operações classificadas a partir de $\mathrm{E}$, inclusive, como as mais arriscadas e utilizaremos a soma dos saldos dessas operações como o numerador do quociente. A escolha desse corte na classificação se deve a que ele representa as operações em atraso por mais de 90 dias e esse é um critério para definir inadimplência, utilizado, por exemplo, pelo Comitê de Basileia para Supervisão Bancária (BIS, 2000). Além disso, a inadimplência é uma forma empregada recorrentemente na literatura para medir o risco das instituições financeiras ${ }^{20}$.

Note que a variável que estamos adotando mede a exposição dos bancos a um risco específico, qual seja, o risco de crédito. Não estamos considerando aqui outros riscos, como o de mercado e operacional. No entanto, o risco de crédito é o principal risco que as instituições financeiras correm no Brasil. Conforme mostra o Relatório de Estabilidade Financeira do BACEN, de outubro de 2009 (pg. 67), dos $\mathrm{R} \$ 201,6$ bilhões de PRE total de todas as instituições autorizadas a operar por aquela Autarquia, 92,7\% são referentes à parcela de risco de crédito.

20 Vide Grossman (1992), Karels e McClatchey (1999), Gropp e Vesala (2004), Nier e Baumann (2006), Angkinand e Wihlborg (2010), Tabak et. al (2012) 


\subsection{Período de vigência do DPGE}

O DPGE foi criado ao final de março de 2009, sendo que os bancos já puderam utilizar esse instrumento a partir do mês seguinte. Levando em conta que nossos dados são semestrais e referentes a junho e dezembro, poderíamos considerar junho de 2009 como o momento a partir do qual o DPGE pôde ter criado um problema de risco moral nos bancos. No entanto, levando em conta que uma de nossas medidas de risco é influenciada pelos atrasos acima de 90 dias nas operações de crédito, e considerando que se o banco passasse já em abril a realizar operações de crédito mais arriscadas o reflexo disso sobre a medida de risco apareceria, muito provavelmente, apenas no balancete de dezembro de 2009, então, o melhor foi considerar que o DPGE possa ter apresentado efeitos no risco a partir dos balancetes de dezembro de 2009 em diante. Ademais, conforme mostra a figura 1, após a criação do DPGE, a captação dos bancos menores ainda levou alguns meses para se recuperar, sugerindo que, se houve um efeito do DPGE sobre os riscos dos bancos, ele não foi imediato. Por isso, consideramos que o DPGE pôde ter influência sobre risco moral a partir de dezembro de 2009.

\subsection{Bancos de maior porte como grupo de controle}

A autorização para emitir o DPGE foi dada a todos os bancos comerciais, múltiplos, de desenvolvimento e de investimento, sociedades de crédito, financiamento e investimento e caixas econômicas. Apesar da medida ter sido adotada para restabelecer a liquidez dos bancos de menor porte, não houve distinção entre bancos maiores e menores.

No entanto, pode-se dizer que o DPGE foi uma medida inócua para os bancos maiores. Como pudemos ver no gráfico da figura 1, esses bancos não tiveram problemas de acesso à liquidez durante a crise. Pelo contrário, tiveram uma abundância de recursos. Ademais, o DPGE tem um custo de emissão maior do que os depósitos a prazo convencionais, uma vez que a contribuição feita junto ao FGC pela emissão do DPGE é maior. Assim, para os bancos grandes, que passavam por uma abundância de liquidez, a criação do DPGE foi uma medida inócua, pois eles poderiam captar recursos a custos menores através dos depósitos convencionais.

Dessa forma, é interessante confrontar os riscos assumidos pelos bancos de menor porte com os riscos dos bancos grandes para tentar identificar o efeito do DPGE sobre o risco moral nos bancos menores. No entanto, existem algumas dificuldades práticas em se fazer essa comparação que merecem ser destacadas.

A primeira delas diz respeito à participação dos bancos públicos ou de economia mista no grupo dos bancos de grande porte (vide tabela 1). Esses bancos 
tiverem um papel anticíclico importante ao final do ano de 2008, e durante 2009, expandindo suas operações de crédito conforme diretriz traçada pelo governo federal (BRASIL, 2009). Isto significa que, tudo o mais constante, essas instituições foram estimuladas a assumirem mais riscos durante o período que faz parte de nossa amostra. Como empregaremos os bancos de grande porte na comparação dos riscos assumidos pelos bancos menores, esse movimento de expansão do crédito dos bancos controlados pelo governo federal pode prejudicar nossa identificação do efeito do DPGE sobre o risco moral nos bancos menores. Por esse motivo, poderíamos considerar a exclusão desses bancos da amostra. No entanto, a expansão do crédito desses bancos não surgiu ao mesmo tempo em que o DPGE. Na realidade, ela tem sua origem ainda em 2008 (BRASIL, 2009). Dessa forma, entendemos que não se trata de um fator que comprometa a identificação do efeito do DPGE.

Em segundo lugar, duas instituições do grupo de bancos de grande porte passaram por processos de fusão dentro do período abarcado por nossa amostra. $\mathrm{Na}$ data-base de dezembro de 2008, Itaú e Unibanco já passaram a divulgar balanços referentes ao novo conglomerado. Por sua vez, ainda ao final de 2008, o Santander Brasil anunciou a compra do Banco Real, aquisição que se reflete na unificação dos demonstrativos contábeis na data-base junho de 2009. Em função desses eventos societários, utilizamos no modelo algumas variáveis de controle baseadas em dados contábeis para capturar eventuais alterações nas medidas de risco decorrentes da consolidação dos balanços das instituições envolvidas nas fusões ou aquisições.

Um terceiro ponto que merece destaque são as capitalizações dos bancos dentro do período de nossa análise. BNDES e Santander são bancos que tiveram aportes de capitais importantes durante esse período. Capitalizações têm impacto direto no índice de Basileia, através do PR, e, portanto, afetam a medida de risco feita através desse índice. Em função disso, em nossa análise empírica consideraremos no modelo uma medida de capitalização das instituições para capturar esse efeito.

\subsection{Cooperativas de crédito como grupo de controle}

Além de utilizar os bancos grandes como base de comparação para os riscos assumidos pelos bancos de menor porte, também tomaremos como referência as cooperativas de crédito. A ideia é dar robustez à nossa análise tomando como grupo de controle um conjunto de entidades que captam recursos através de depósitos a prazo e assumem riscos nas suas operações ativas, mas que não tiverem a opção de emitir DPGE ${ }^{21}$.

$21 \mathrm{Na}$ realidade, os passivos das cooperativas de crédito não têm cobertura do FGC. Para haver cobertura, algumas cooperativas aderem a sistemas garantidores próprios, como o Fundo Garantidor do Sicoob, ligado ao Sistema das Cooperativas de Crédito do Brasil (Sicoob). Mas mesmo nesses sistemas não houve medidas 
De acordo com Pinheiro (2008), as cooperativas de crédito são classificadas de três formas. Podem ser cooperativas singulares, que prestam serviços de depósitos e empréstimos diretamente aos seus associados; cooperativas centrais, quando uma instituição reúne um conjunto de cooperativas singulares para prestar serviços assistenciais diversos. Finalmente, temos as confederações cooperativas, compostas por cooperativas centrais e que "têm por objetivo orientar e coordenar as atividades das filiadas (...)" (PINHEIRO, 2008, pg. 7). Dado que são as cooperativas singulares que realizam as operações de captação e empréstimo de recursos, empregaremos essas instituições e nossa análise empírica desconsiderando as cooperativas centrais e as confederações cooperativas. Isso significa trabalhar com um conjunto de instituições que somam aproximadamente $R$ \$21 bilhões em operações de crédito, considerando dados de junho de $2009^{22}$.

\subsection{Variáveis de controle}

Com o objetivo de garantir a eficiência e consistência dos estimadores utilizados para capturar o efeito do DPGE sobre os riscos assumidos pelos bancos, vamos considerar um conjunto de variáveis de controle que estão divididas conforme elas possam assumir valores diferentes para cada banco e cooperativa, ou o mesmo valor para todas as instituições em um determinado instante do tempo. No primeiro caso temos as variáveis ao nível da firma, que denominaremos de micro-controles. Por sua vez, o segundo grupo é representado por variáveis em nível agregado, denominado de macro-controles.

\subsubsection{Controles ao nível da firma (micro-controles)}

Um dos micro-controles empregados é a relação entre o saldo das operações de crédito do banco e seu ativo circulante e realizável a longo prazo, a qual representamos por opercred. A presença desta variável no modelo é particularmente importante quando medimos o risco do banco a partir das classificações das operações de crédito. Como essa medida de risco é o quociente entre o saldo das operações classificadas em E, F, G ou H sobre o total das operações, podemos ter uma situação onde risco do banco está aumentando, mas a medida de risco indica o contrário por conta do crescimento do denominador, sem aumento no numerador. Isto acontece, por exemplo, se novas operações forem classificadas em níveis de risco menores que E. Nesta situação, a inclusão da variável opercred no modelo capturará a queda da medida de risco porque aquela variável estará crescendo ao análogas à criação do DPGE.

22 A título de referência, no mesmo período os bancos de menor porte somavam aproximadamente $\mathrm{R} \$ 250$ biIhões em operações de crédito. 
mesmo tempo em que esta se reduz. Cabe mencionar que esta variável também foi empregada como controle nos estudos de Keeley (1990) e Gropp e Vesala (2004).

Um segundo micro-controle empregado é a capitalização da instituição, denominada captlz, medida pelo valor do patrimônio líquido sobre o ativo (circulante e permanente). Quanto maior for a importância do capital do banco como fonte de recursos para suas operações ativas menor deve ser o efeito do DPGE e do risco moral, uma vez que o banco passa a arcar com uma parcela maior das perdas incorridas. Nesse sentido, pode-se esperar que essa variável tenha um efeito negativo sobre os riscos assumidos pelo banco.

No entanto, devemos notar que essa variável pode servir para controlar efeitos associados à forma como são construídas as medidas de risco. No caso do risco medido através das classificações de crédito, pode existir um efeito similar ao mencionado com relação a opercred. Como captlz é uma relação entre o patrimônio líquido o ativo, se o banco aumentar suas operações de crédito classificadas entre AA e D com recursos captados através de depósitos, então, tudo o mais constante, o ativo aumenta e a captiz cai. Mas esse movimento é acompanhado por uma queda da medida de risco, conforme mencionamos acima, de modo que podemos ter um coeficiente positivo para captlz. Por sua vez, considerando o índice de Basileia (IB), esse índice é função crescente do patrimônio de referência (PR), que é composto pelo patrimônio líquido. Logo, em uma situação onde uma instituição aumente seu capital, sua medida de risco cairá (o IB subirá), considerando tudo o mais constante. Mas pode ser que essa instituição tenha mantido inalterado o nível de risco das suas operações, de modo que a elevação do IB seria um movimento incorreto para o que estamos querendo medir, que é nível de risco. Assim, inserindo a capitalização como uma variável explicativa também buscamos capturar esse efeito, o que implica dizer que podemos ter para essa variável um coeficiente positivo.

Seguindo Gropp e Vesala (2004), inserimos também como micro-controle a relação entre o valor do ativo do banco e a soma dos ativos de todos os bancos, definida como tam. O objetivo é capturar um possível efeito de "to big to fail", onde um grande banco poderia assumir maiores riscos pressupondo que as autoridades reguladoras não permitiriam a sua quebra dado o impacto que ela teria sobre as demais instituições do sistema bancário. Ademais, autores como Nier e Baumann (2006) apontam que bancos maiores tendem a manter menores níveis de capital. Logo, especialmente quando o risco for medido pelo índice de Basileia, que depende do capital mantido pela instituição, utilizar o porte do banco como 
variável explicativa é importante para filtrar seu efeito sobre a medida de risco.

Outra variável de controle utilizada é a relação entre depósitos a prazo e passivo, dada por depprz. O objetivo é medir a relevância desses depósitos dentro das fontes de captação dos bancos. Os depósitos a prazo são uma fonte onerosa de recursos quando comparados aos depósitos à vista e de poupança. Dessa forma, estando os bancos sujeitos a uma disciplina de mercado onde exista uma relação direta positiva entre os custos de captação e os riscos assumidos pelas instituições, então, bancos com maior dependência dos depósitos a prazo devem apresentar níveis menores de risco, considerando tudo o mais constante. Portanto, o sinal esperado para essa variável é negativo. Vale mencionar, que essa variável foi utilizada nos trabalhos de Keeley (1990) e Gropp e Vesala (2004).

Por último, utilizamos também como controle uma medida de eficiência dada pela razão entre as receitas e as despesas operacionais (chamada de efncia). Empregamos essa variável porque bancos mais eficientes podem assumir riscos menores em relação aos bancos menos eficientes para obter determinados resultados, de modo que o coeficiente dessa variável deve ser negativo.

\subsubsection{Controles ao nível agregado (macro-controles)}

Para controlar possíveis efeitos agregados que possam influenciar os riscos assumidos pelos bancos consideramos o PIB semestral e o seu crescimento, representados por pib6m e varpib. O objetivo é capturar o crescimento do risco devido a um otimismo com a expansão econômica que faça com que os agentes econômicos e as instituições financeiras demandem e ofertem mais crédito, respectivamente. Neste caso, o sinal esperado para os coeficientes dessas variáveis é positivo.

Também colocamos no modelo o crescimento do crédito agregado em seis meses, representado por varcred6m. Essa variável tem como objetivo capturar dois efeitos. O primeiro deles seria análogo ao que temos com as duas variáveis anteriores, isto é, o buscamos um crescimento do risco devido a uma euforia dos agentes que se traduz em crescimento do crédito agregado da economia. O segundo efeito está relacionado à medida de risco baseada nas classificações de crédito. Neste caso, o controle tem o papel de complementar à função desempenhada pela variável opercred que discutimos a acima, isto é, queremos capturar a queda da medida de risco decorrente da expansão das operações de crédito controlando pelo efeito de expansão do denominador da medida de risco. Nesse sentido, aliás, o coeficiente esperado para essa variável é negativo.

Um terceiro macro-controle empregado é a taxa de juros real de um ano, 
representada por juroreal, obtida das aplicações em ativos de baixo risco (títulos públicos federais). Considerando que esses investimentos reduzem o risco dos bancos quando comparados às operações de crédito, a inclusão dessa taxa de juros reflete o custo de oportunidade das instituições em assumir riscos. Dessa forma, espera-se que o sinal do coeficiente dessa variável seja negativo.

Também consideramos como controle o nível agregado de inadimplência, denominado inad. Para esta variável não temos um sinal esperado, uma vez que ela pode tanto representar, quando cresce, um indicativo para as instituições financeiras reduzirem os riscos, pois a situação geral dos tomadores de recursos estaria se deteriorando, como pode representar uma relação positiva, se pensarmos na medida de risco baseada nas classificações de crédito, que tem um componente de inadimplência embutido na sua definição.

Por fim, colocamos o logaritmo natural do nível dos recolhimentos compulsórios incidentes sobre as instituições financeiras, representada por comp. O sinal esperado para o coeficiente dessa variável é negativo, uma vez que os recolhimentos compulsórios limitam a exposição a riscos dos bancos. No entanto, cabe mencionar que as cooperativas de crédito não sofrem esses recolhimentos compulsórios de maneira que quando estivermos empregando as cooperativas em nossas análises a variável comp será não-nula apenas para os bancos.

É importante notar que algumas das variáveis que elencamos aqui podem estar correlacionadas entre si. Nesses casos, bastaria considerar um subconjunto dessas variáveis para capturar os efeitos agregados sobre as medidas de risco. De fato, como veremos nos resultados econométricos, algumas variáveis não se mostraram relevantes quando consideradas em conjunto com outras variáveis.

\subsubsection{Variáveis explicativas endógenas}

O estimador proposto por Arellano e Bond (1991) pressupõe que as variáveis explicativas sejam sequencialmente exógenas, o que significa que os regressores não devem ser correlacionados com os termos aleatórios do presente e do futuro. Logo, é preciso discutir se no caso das variáveis consideradas neste trabalho essa hipótese é válida.

No caso dos controles macroeconômicos é razoável supor que eles sejam estritamente exógenos em relação ao termo aleatório $u_{i t}$, o que significa dizer que nenhum banco isoladamente influencia com sua decisão de assumir riscos as variáveis macroeconômicas consideradas.

Com relação às variáveis que representam o período em que o DPGE pode 
ter exercido efeito sobre os riscos assumidos pelos bancos, $d_{t} \mathrm{e} D_{i t}$, também assumiremos que elas são estritamente exógenas uma vez que o DPGE foi criado para lidar com problemas de liquidez dos bancos que surgiram em função da crise financeira internacional, que é um evento exógeno.

No caso dos micro-controles vale relembrar que estamos utilizando a capitalização da instituição, o tamanho dela, a proporção dos depósitos a prazo em relação ao passivo, a proporção das operações de crédito em relação ao ativo e a sua eficiência. Por se tratar de dados contábeis, a ocorrência de choques aleatórios futuros nos riscos assumidos pelas instituições financeiras não afetam essas variáveis no presente e no passado. No entanto, choques aleatórios no presente podem afetar essas variáveis também no presente. Por exemplo, se um banco for surpreendido com uma inadimplência inesperada em determinado semestre, isso provavelmente fará crescer sua medida de risco baseada nas classificações de crédito ao mesmo tempo em que afetará também sua capitalização e eficiência. Por sua vez, considerando o risco medido pelo índice de Basileia, esse índice é calculado com base nas operações que as instituições realizam e essas operações também afetam as contas dos balancetes dessas instituições. Dessa forma, é possível que um choque aleatório sobre o índice também tenha efeito sobre os micro-controles. Assim, vemos que nossos micro-controles não são sequencialmente exógenos, de modo que utilizaremos como instrumentos para essas variáveis as suas defasagens, conforme proposto por Arellano e Bond (1991).

Finalmente, cabe destacar que a variável dependente defasada utilizada como regressor do modelo também não atende ao pressuposto de exogeneidade seqüencial. Também aqui utilizaremos como instrumento desse regressor as suas defasagens segundas e posteriores.

\section{FONTE DE DADOS E ANÁLISE DESCRITIVA}

Os dados utilizados neste trabalho foram extraídos dos balancetes semestrais das instituições que compõem o sistema bancário brasileiro no período entre junho de 2007 a dezembro de 2010 e estão disponíveis no sítio do Banco Central do Brasil. Também foram obtidos da mesma fonte e para o mesmo período os balancetes das cooperativas de crédito.

Desejamos analisar o efeito da criação do DPGE sobre as exposições de risco dos bancos e escolhemos o período destacado acima porque com ele conseguimos um maior conjunto de dados. Antes de junho de 2007 e após dezembro de 2010 alguns bancos deixam de existir ou são incorporados por outros bancos 
de modo que para manter o maior número de instituições na amostra nos restringimos ao período entre essas duas datas.

É importante destacar que no caso dos bancos, os dados utilizados são dos conglomerados financeiros, quando eles existirem. No entanto, por simplicidade, ao longo do texto empregaremos a expressão "banco" para nos referirmos tanto às instituições individuais quanto aos conglomerados, quando não for necessária uma distinção entre eles.

Outra informação coletada junto ao Banco Central do Brasil foi o índice de Basileia de cada instituição no período entre julho de 2008 e dezembro de $2010^{23}$. O motivo de considerarmos o índice de Basileia a partir de uma data posterior aos dos demais dados está em que antes de julho de 2008 a fórmula de cálculo do índice sofreu alterações, impossibilitando a comparação da métrica.

Com esse conjunto de informações foram construídas quatro bases de dados com duas medidas de risco e dois grupos de controle. Relacionada à medida de risco baseada nas classificações de crédito temos duas bases de dados, uma com 115 bancos, sendo oito de grande porte, e outra com 107 bancos de menor porte e 202 cooperativas de crédito. Por sua vez, as outras duas bases utilizam o índice de Basileia como medida de risco, sendo uma delas formada por 118 bancos, também com oito bancos de grande porte ${ }^{24}$, e a outra composta por 110 bancos de menor porte e 202 cooperativas de crédito ${ }^{25}$.

Para visualizar o comportamento temporal das medidas de risco deste trabalho separamos os bancos em instituições de grande e menor porte, conforme discutimos, e calculamos a média das medidas de risco para esses dois grupos de bancos e para as cooperativas de crédito. O comportamento da medida de risco baseada na classificação dos créditos pode ser observado na figura 2.

23 O índice de Basileia (IB) dos bancos é divulgado pelo Banco Central do Brasil em seu sítio na internet. O IB das cooperativas, por sua vez, teve que ser solicitado àquela Autarquia.

24 O número de bancos de menor porte é diferente da amostra anterior porque tanto para as classificações de crédito, como para os índices de Basileia, algumas instituições não traziam essas informações, sendo excluías da amostra. 25 Com relação às cooperativas presentes na amostra, elas representam noventa por cento do total de operações de crédito de todas as cooperativas, tomando como referência informações de junho de 2009. Não foram incluídas nas amostras as cooperativas de baixa relevância, em termos do volume de operações que realizam, ou aquelas com dados faltantes. 
Figura 2 - Inadimplência e média da medida de risco baseada nas classificações de crédito

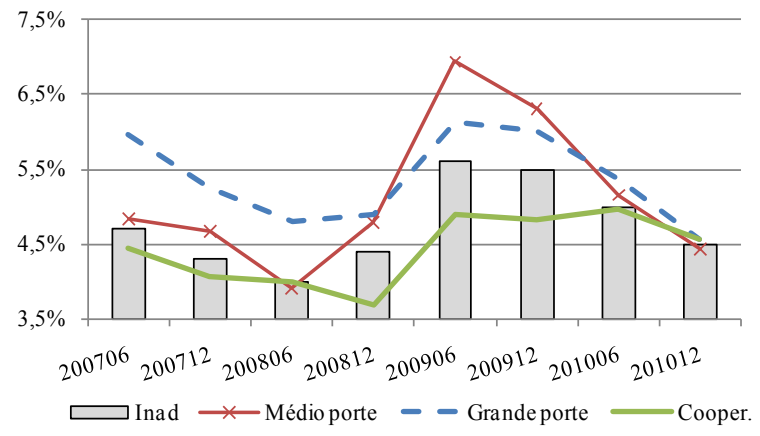

Fonte: Banco Central do Brasil

Pela figura 2 vemos que as medidas de risco dos bancos e das cooperativas sobem em junho de 2009 para depois recuarem, com exceção das cooperativas que se mantém em patamar elevado. Analisando os dados agregados de crédito percebemos que esse o movimento se reflete na inadimplência calculada pelo BACEN e que pode ser visualizada na figura 2 (representada por inad). Como era esperado, existe um movimento conjunto das séries de risco e de inadimplência. A medida de risco baseada em classificações de crédito é determinada, em parte, pelos atrasos nos pagamentos de principal e de juros de empréstimos e financiamentos. Como esses atrasos definem a inadimplência, existe uma correlação entre essas variáveis decorrente da forma como elas são construídas o que justifica a inclusão da inadimplência como controle na estimação do efeito do DPGE sobre os bancos.

Quanto à medida de risco feita através do índice de Basileia, a figura 3 mostra a evolução das séries dos bancos de grande e menor porte e a figura 4 dos bancos de menor porte e das cooperativas.

Figura 3 - Média dos índices de Basileia dos bancos de grande e de menor porte

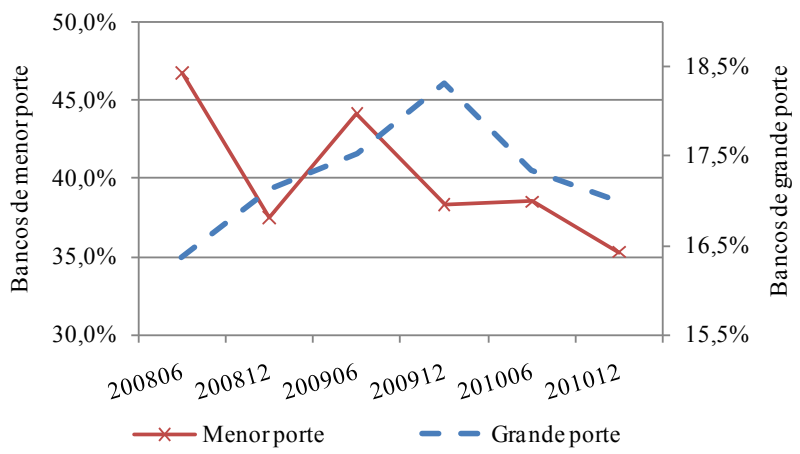

Fonte: Banco Central do Brasil 
Figura 4 - Média dos índices de Basileia das Cooper. de crédito e dos bancos de menor porte

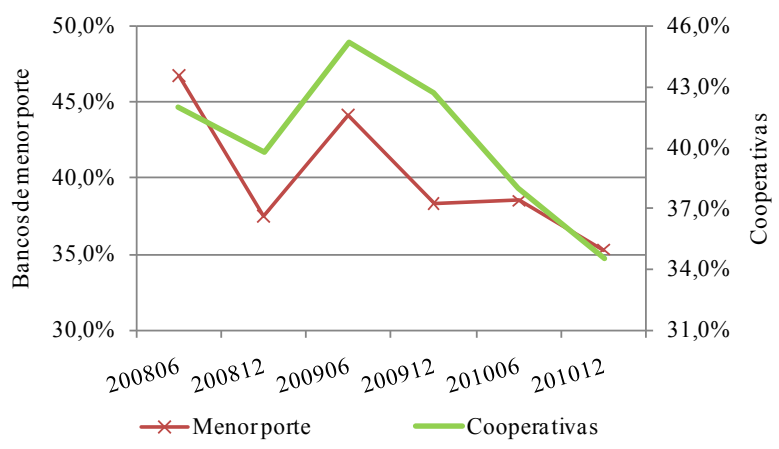

Fonte: Banco Central do Brasil

Destaca-se na figura 3 a diferença de nível das medidas de risco entre os bancos de menor e de grande porte, sendo que os bancos de menor porte possuem índices de Basileia relativamente maiores que os dos bancos de grande porte. Isso reflete os diferentes perfis de risco das operações realizadas por essas instituições, mas também o nível de capitalização das mesmas. Em principio essas diferenças de nível nas medidas de risco poderiam ser tratadas em nosso modelo econométrico diferenciado os portes dos bancos com uma variável dummy. No entanto, como estamos trabalhando com um modelo que prevê efeitos idiossincráticos de cada instituição, esses diferenciais de nível das medidas de risco serão capturados por esse termo, de modo que não é necessária a inclusão daquela variável no modelo.

Um segundo ponto a ser notado na figura 3 é o movimento ascendente do índice de Basileia médio dos bancos de grande porte. Em princípio, esse movimento sugere uma redução dos riscos assumidos por aqueles bancos. No entanto, ele é decorrente de um outlier na amostra. Como podemos observar na figura 5, o índice de Basileia do Santander apresenta uma expressiva elevação decorrente da fusão de suas operações com o Banco Real, no segundo semestre de 2008, e da emissão de ações, no segundo semestre de 2009. 
Figura 5 - Índices de Basileia das instituições do grupo de bancos de grande porte
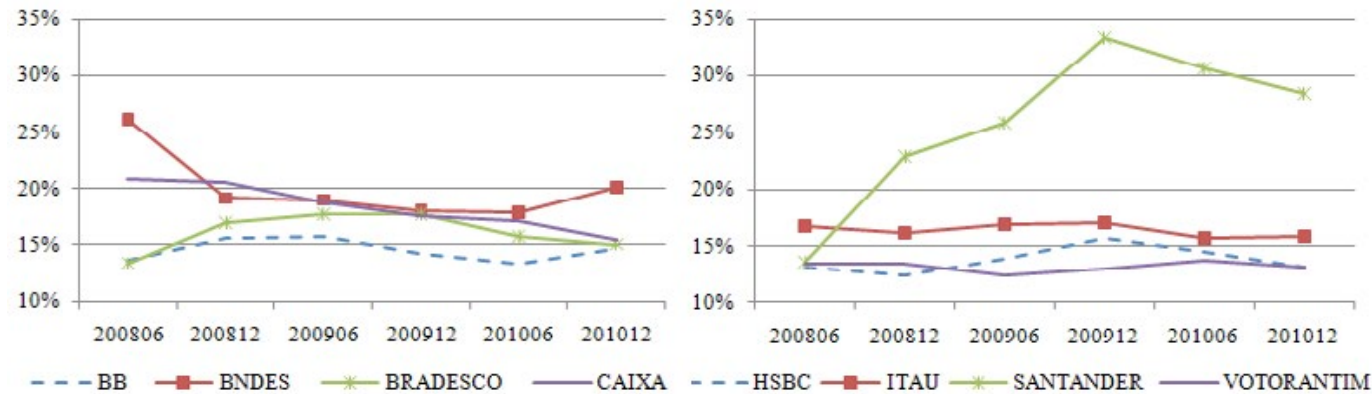

Esse movimento do índice de Basileia do Santander é um exemplo do que discutimos anteriormente sobre as dificuldades práticas de utilizar os bancos de maior porte como grupo de controle. No entanto, ainda conforme o que foi discutido, os efeitos desses eventos societários sobre as medidas de risco serão capturados no modelo estatístico com variáveis de controle construídas a partir de informações dos balancetes das instituições, tais como uma medida de capitalização da instituição.

\section{RESULTADOS EMPÍRICOS}

Nesta seção apresentaremos as estimativas obtidas do modelo econometrico, separando por medida de risco e grupo de controle.

\subsection{Risco pelas classificações de crédito e bancos de grande porte como grupo de controle}

Com relação aos controles-macro, o modelo foi estimado considerando diversas especificações. A inclusão de todas as variáveis no modelo mostrou que diversas delas não eram significantes. Por sua vez, quando as variáveis eram consideradas uma a uma seus coeficientes apresentaram-se estatisticamente diferentes de zero. Assim, fizemos diversas composições de variáveis e identificamos os modelos com os seguintes pares de variáveis (varpib, varcred6m), (varpib,inad) e (varcred6m, comp) como os mais adequados, com base dos testes de especificação ${ }^{26}$. Em seguida, partimos dessas especificações para inserir os micro-controles. Os resultados mostraram que, uma vez controlados os efeitos agregados, os coeficientes estimados dos micro-controles não eram estatisticamente diferentes de zero em diversos casos. As exceções foram as variáveis captlz e depprz, significantes aos níveis de confiança de 1,\% 2,5\% e 5\%. A tabela 2 traz os modelos estimados mais adequados com base nos testes de especificação.

26 Realizamos testes da significância dos coeficientes, da exogeneidade dos instrumentos (ARELLANO e BOND 1991, pg. 282) e da ausência de autocorrelação de segunda ordem das primeiras diferenças dos choques aleatórios. 
O DEPÓSITO A PRAZO COM GARANTIA ESPECIAL E O RISCO MORAL NOS BANCOS BRASILEIROS: UMA ANÁLISE EMPÍRICA COM DADOS DE PAINEL

Tabela 2 - Controle nos bancos de grande porte e risco baseado nas classificações de crédito

\begin{tabular}{|c|c|c|c|c|c|c|c|c|c|c|}
\hline & $\operatorname{AR}(2)^{\#}$ & $\begin{array}{c}\text { Sargan/ } \\
\text { Hansen }\end{array}$ & $y_{(t-1)}$ & $d_{t}$ & $D_{t i}$ & varcred $6 m$ & inad & сотp & captlz & deppraz \\
\hline (i) & 0.521 & 0.913 & $\begin{array}{l}0.804^{*} \\
(0.128)\end{array}$ & $\begin{array}{l}-0.004 \\
(0.007)\end{array}$ & $\begin{array}{l}-0.003 \\
(0.009)\end{array}$ & $\begin{array}{l}-0.219^{*} \\
(0.066)\end{array}$ & & & $\begin{array}{c}0.819 * \\
(0.219)\end{array}$ & $\begin{array}{l}-0.105^{*} \\
(0.034)\end{array}$ \\
\hline (ii) & 0.519 & 0.210 & $\begin{array}{l}0.559^{*} \\
(0.081)\end{array}$ & $\begin{array}{l}-0.012 * \\
(0.005)\end{array}$ & $\begin{array}{c}0.002 \\
(0.006)\end{array}$ & & $\begin{array}{c}1.14 * \\
(0.252)\end{array}$ & & $\begin{array}{c}0.559 * * \\
(0.25)\end{array}$ & $\begin{array}{c}-0.082 * * * \\
(0.038)\end{array}$ \\
\hline (iii) & 0.642 & 0.652 & $\begin{array}{l}0.544^{*} \\
(0.076) \\
\end{array}$ & $\begin{array}{l}-0.001 \\
(0.005) \\
\end{array}$ & $\begin{array}{c}0.003 \\
(0.006) \\
\end{array}$ & $\begin{array}{l}-0.192 * \\
(0.045) \\
\end{array}$ & & $\begin{array}{l}-0.005 \\
(0.007) \\
\end{array}$ & $\begin{array}{c}0.696^{*} \\
(0.215) \\
\end{array}$ & $\begin{array}{l}-0.106^{*} \\
(0.038) \\
\end{array}$ \\
\hline
\end{tabular}

\#p-valor

Significância: $* 1 \%, * * 2,5 \%, * * * 5 \%, * * * * 10 \%$ (desvios-padrão entre parênteses)

Com relação ao efeito do DPGE sobre os riscos assumidos pelos bancos menores, a variável que representa esse efeito apresentou coeficientes estatisticamente nulos nas diversas especificações. Assim, não encontramos evidências de que o DPGE tenha produzido um aumento nos riscos assumidos pelos bancos de menor porte na comparação com os bancos maiores.

\subsection{Risco pelas classificações de crédito e cooperativas de crédito como grupo de controle}

A abordagem de estimação quando as cooperativas de crédito formam o grupo de controle dos riscos assumidos pelos bancos menores seguiu a mesma adotada na seção anterior. Os resultados das estimativas considerando a inclusão dos controles macro e micro no modelo são mostrados na tabela 3.

Como pode ser observado, o efeito do DPGE sobre os riscos assumidos pelos bancos, capturado por , não se mostrou significante nas diversas especificações testadas. Portanto, assim como ocorreu na seção anterior não encontramos evidências de que o DPGE tenha causado um aumento nos riscos assumidos pelos bancos.

Tabela 3 - Controle com cooperativas de crédito e risco baseado nas classificações de crédito

\begin{tabular}{|c|c|c|c|c|c|c|c|c|c|c|}
\hline & $\operatorname{AR}(2)^{\#}$ & $\begin{array}{c}\text { Sargan/ } \\
\text { Hansen }\end{array}$ & $y_{(t-1)}$ & $d_{t}$ & $D_{t i}$ & varcred $6 m$ & сотp & inad & $\operatorname{captz}(-1)$ & $\begin{array}{c}\text { opercred } \\
(-1)\end{array}$ \\
\hline (i) & 0.214 & 0.372 & $\begin{array}{l}0.719^{*} \\
(0.188)\end{array}$ & $\begin{array}{c}-0.002 \\
(0.003)\end{array}$ & $\begin{array}{l}-0.005 \\
(0.006)\end{array}$ & $\begin{array}{l}-0.108^{*} \\
(0.016)\end{array}$ & $\begin{array}{l}-0.014^{*} \\
(0.005)\end{array}$ & & $\begin{array}{c}0.143 * * * \\
(0.066)\end{array}$ & \\
\hline (ii) & 0.210 & 0.662 & $\begin{array}{l}0.747^{*} \\
(0.135)\end{array}$ & $\begin{array}{l}-0.002 \\
(0.003)\end{array}$ & $\begin{array}{l}-0.007 \\
(0.006)\end{array}$ & $\begin{array}{l}-0.107^{*} \\
(0.024)\end{array}$ & $\begin{array}{l}-0.015^{*} \\
(0.006)\end{array}$ & & & $\begin{array}{c}0.020 \\
(0.039)\end{array}$ \\
\hline (iii) & 0.223 & 0.457 & $\begin{array}{l}0.709^{*} \\
(0.207)\end{array}$ & $\begin{array}{l}-0.004 \\
(0.003)\end{array}$ & $\begin{array}{l}-0.007 \\
(0.006)\end{array}$ & $\begin{array}{l}-0.064^{*} \\
(0.024)\end{array}$ & & $\begin{array}{c}0.439 * * \\
(0.186)\end{array}$ & $\begin{array}{c}0.156^{* * *} \\
(0.071)\end{array}$ & \\
\hline (iv) & 0.221 & 0.699 & $\begin{array}{l}0.708^{*} \\
(0.136) \\
\end{array}$ & $\begin{array}{c}-0.003 \\
(0.003) \\
\end{array}$ & $\begin{array}{l}-0.009 \\
(0.006) \\
\end{array}$ & $\begin{array}{l}-0.069^{*} \\
(0.025) \\
\end{array}$ & & $\begin{array}{l}0.409^{*} \\
(0.159) \\
\end{array}$ & & $\begin{array}{c}0.03 \\
(0.036) \\
\end{array}$ \\
\hline
\end{tabular}




\subsection{Risco pelo índice de Basileia e bancos de grande porte como grupo de controle}

Ao utilizar o índice de Basileia como nossa medida de risco, notamos em diversas especificações testadas que o termo auto-regressivo foi o principal fator a explicar os movimentos da variável dependente. Por sua vez, os micros e macros controles mostraram baixa significância ou não rejeitaram a hipótese nula de que seus coeficientes eram iguais a zero.

Em função da baixa importância dos controles no modelo, estimamos o efeito do DPGE sobre os riscos dos bancos inserindo as variáveis dummies que representam o efeito agregado que pode ter ocorrido quando o DPGE foi criado, $d_{\mathrm{t}}$, e o efeito do DPGE sobre os bancos de menor porte, $D_{\text {it" }}$.

Tabela 4 - Controle com bancos de grande porte e risco baseado nos índices de Basileia.

\begin{tabular}{|c|c|c|c|c|c|c|}
\hline & $\operatorname{AR}(2)^{\#}$ & $\begin{array}{l}\text { Sargan/ } \\
\text { Hansen }\end{array}$ & $y_{(t-I)}$ & $d_{t}$ & $D_{t i}$ & pib6m \\
\hline (i) & 0.499 & 0.717 & $\begin{array}{c}0.305 * \\
(0.041)\end{array}$ & & & \\
\hline (ii) & 0.652 & 0.680 & $\begin{array}{l}0.212 * \\
(0.08)\end{array}$ & $\begin{array}{l}-0.064 \\
(0.042)\end{array}$ & & \\
\hline (iii) & 0.661 & 0.677 & $\begin{array}{c}0.208 * * \\
(0.084)\end{array}$ & & $\begin{array}{l}-0.069 \\
(0.045)\end{array}$ & \\
\hline (iv) & 0.661 & 0.678 & $\begin{array}{c}0.208 * * \\
(0.083)\end{array}$ & $\begin{array}{c}0.007 \\
(0.009)\end{array}$ & $\begin{array}{l}-0.076 \\
(0.046)\end{array}$ & \\
\hline (v) & 0.532 & 0.733 & $\begin{array}{c}0.271^{*} \\
(0.036) \\
\end{array}$ & & & $\begin{array}{c}-0.002 * * * * \\
(0.001) \\
\end{array}$ \\
\hline
\end{tabular}

Conforme podemos observar na tabela 4 , as variáveis $d_{\mathrm{t}}$ e $D_{\mathrm{it}}$ não mostraram coeficientes estatisticamente diferentes de zero, sugerindo que o DPGE não aumentou os riscos assumidos pelos bancos de menor porte quando comparados com os riscos dos bancos maiores.

\subsection{Risco pelo índice de Basileia e cooperativas de crédito como grupo de controle}

De maneira similar aos resultados encontrados na seção anterior, onde a variável dependente defasada se mostrou estatisticamente significante nas diversas especificações testadas em detrimento de outros controles macros e micros, agora, com a base de dados composta por bancos de menor porte e cooperativas, também o risco medido pelo índice de Basileia teve na variável dependente defa- 
sada um fator explicativo recorrentemente significante. No entanto, notamos que foi necessário distinguir no modelo os bancos das cooperativas para identificar o coeficiente desse fator. Para tanto, consideramos que os micro-controles tinham coeficientes diferentes para bancos e para as cooperativas de maneira a conseguir separar a amostra entre esses dois grupos.

Tabela 5 - Controle com cooperativas de crédito e risco baseado nos índices de Basileia.

\begin{tabular}{|c|c|c|c|c|c|c|c|}
\hline & $\operatorname{AR}(2)^{\#}$ & $\begin{array}{l}\text { Sargan/ } \\
\text { Hansen }\end{array}$ & $y(t-1)$ & $d_{t}$ & $D_{t i}$ & varpibl & ccaptlz \\
\hline (i) & 0.282 & 0.700 & $\begin{array}{c}0.197 * \\
(0.038)\end{array}$ & $\begin{array}{c}0.001 \\
(0.025)\end{array}$ & $\begin{array}{l}-0.067 \\
(0.07)\end{array}$ & $\begin{array}{c}-0.531 * * * \\
(0.261)\end{array}$ & \\
\hline (ii) & 0.330 & 0.295 & $\begin{array}{c}0.177^{*} \\
(0.042)\end{array}$ & & $\begin{array}{c}-0.08 \\
(0.112)\end{array}$ & & $\begin{array}{l}4.019^{*} \\
(1.18)\end{array}$ \\
\hline (iii) & 0.808 & 0.388 & $\begin{array}{c}0.118 \\
(0.295)\end{array}$ & $\begin{array}{c}-0.039 * * * * \\
(0.021)\end{array}$ & & & $\begin{array}{c}3.497 * * * * \\
(1.979)\end{array}$ \\
\hline (iv) & 0.311 & 0.274 & $\begin{array}{c}0.178^{*} \\
(0.039) \\
\end{array}$ & $\begin{array}{r}-0.029 \\
(0.024) \\
\end{array}$ & $\begin{array}{r}-0.051 \\
(0.122) \\
\end{array}$ & & $\begin{array}{l}3.246^{* *} \\
(1.377) \\
\end{array}$ \\
\hline
\end{tabular}

A tabela 5 os resultados das especificações mais adequadas, onde a variável ccaptlz se refere à capitalização das cooperativas de crédito. Analisando o efeito do DPGE sobre os riscos assumidos pelos bancos menores, podemos observar que as estimativas do coeficiente da variável $D_{\text {it }}$ não foram estatisticamente diferentes de zero nas diversas especificações testadas. Dessa forma, não encontramos evidências de que o DPGE tenha feito com que os bancos menores assumissem maiores riscos, tendo como base de comparação os riscos assumidos pelas cooperativas de crédito.

\section{INTERPRETAÇÃO DOS RESULTADOS}

Como vimos na seção anterior, não encontramos evidências de que o DPGE criou um problema de risco moral nos bancos de menor porte no Brasil. Esse resultado pode surpreender, dado que a expansão da cobertura do seguro depósito foi significativa e o DPGE serviu efetivamente para restabelecer o acesso daqueles bancos à liquidez em moeda local. Contudo, uma explicação para esses resultados pode estar nos mitigadores do risco moral que existem no sistema bancário brasileiro.

Os mitigadores do risco moral podem atuar de três maneiras: (i) fortalecendo a disciplina de mercado; (ii) aumentando a participação do banco em eventuais perdas que ele sofra; ou (iii) limitando os riscos das operações. No primeiro item se 
encaixa fazer o prêmio do seguro sensível aos riscos incorridos pelo banco. Neste caso, a instituição não pode apenas se preocupar com o retorno dos ativos, uma vez que o custo do seguro aumenta com o risco e consome a rentabilidade das operações. Também fortalece a disciplina de mercado o controle da cobertura do seguro depósito e do volume total de emissão de depósitos segurados, de modo que o banco tenha que recorrer a outras fontes de recursos não contempladas pelo seguro. No item (ii), o mitigador empregado é o requerimento de capital. Seu papel é reduzir a alavancagem do banco e, consequentemente, fazer com que uma parcela maior de recursos próprios (e menor de terceiros) seja afetada em caso de perdas com as operações ativas. Finalmente, quanto ao item (iii), a limitação dos riscos é feita por meio de restrições sobre as operações ativas do banco, sendo o mais comum a imposição de recolhimentos compulsórios sobre os depósitos. Ademais, esse item também é executado através do monitoramento da instituição e dos seus riscos, combinado com a competência do supervisor bancário de impor restrições sobre a gestão do banco em função do resultado daquele monitoramento.

No caso do sistema bancário brasileiro, o item (i) não está presente na definição do prêmio do DPGE, fixado em 0,0833\% a.m. independentemente dos riscos assumidos pelo banco emissor do depósito. No entanto, ainda assim os bancos estão expostos à disciplina de mercado, pois o DPGE tem um limite de emissão por banco ${ }^{27}$. A partir desse limite, a instituição precisa utilizar outras formas de captação que não possuam a cobertura do seguro depósito, ou que possuam coberturas muito menores do que as do DPGE, fazendo com que o banco se exponha à disciplina de mercado.

Quanto ao item (ii), os requerimentos de capital dos bancos no Brasil são calculados com base nos riscos assumidos pelas instituições. Dessa forma, a participação do capital próprio de um banco no financiamento das suas operações cresce com os riscos dessas operações e isso significa que, tudo o mais constante, quanto maior a exposição a risco do banco, maior o volume de recursos próprios que ele pode perder, caso os riscos das operações que ele realizou se materializem. Logo, também temos no requerimento de capital um fator que pode explicar os resultados empíricos obtidos.

Finalmente, com relação ao item (iii), os bancos no Brasil estão sujeitos aos recolhimentos compulsórios sobre os depósitos a prazo (entre outros depósitos). Assim, parte dos recursos captados pelos bancos é direcionada para ativos de risco baixo ou nulo, como os títulos públicos federais ou depósitos junto ao Banco Central, mitigando o risco moral associado ao DPGE. Além disso, o Banco Central exerce o monitoramento e a supervisão dos riscos dos bancos e possui a facul27 Vide Resolução CMN n 3.692, de 26 de março de 2009, e alterações posteriores. 
dade de impor medidas restritivas sobre a gestão das instituições financeiras ${ }^{28}$. Adicionalmente, as instituições financeiras possuem um limite de exposição por cliente ${ }^{29}$, de caráter prudencial, pelo qual uma instituição não pode ter mais do que $25 \%$ de seu PR exposto ao risco de crédito de uma determinada pessoa física ou jurídica. Portanto, também aqui temos elementos que ajudam a explicar porque não encontramos evidências de que o DPGE criou um problema de risco moral nos bancos de menor porte.

Deve-se notar que, muito embora os fatores elencados nos parágrafos acima sirvam como mitigadores do risco moral e ajudem a explicar porque não encontramos evidências desse risco neste trabalho, seria importante conhecer a eficácia individual de cada um desses fatores. Essa informação permitiria aos formuladores de políticas saber, por exemplo, se um relaxamento dos requerimentos de capital, como o que se está produzindo agora com a redução do índice de Basileia de onze para oito por cento, poderia criar um problema de risco moral em um contexto onde exista um seguro depósito nos termos do presente no DPGE. No entanto, uma análise desse tipo foge ao escopo deste trabalho pelo que a deixamos como uma sugestão para pesquisas futuras.

\section{CONCLUSÃO}

Neste trabalho testamos se a criação do DPGE, e a expansão da cobertura do seguro depósito que ele trouxe, criou um problema de risco moral nos bancos de menor porte. Nossa análise comparou os riscos assumidos pelos bancos de menor porte com dois grupos de controles: os bancos de maior porte, para os quais argumentamos que o DPGE representou uma medida inócua; e as cooperativas de crédito, que compartilham com os bancos das características de captarem por depósitos a prazo e realizarem operações de crédito, mas para as quais o DPGE não foi disponibilizado. Nessa análise utilizamos duas medidas de risco, sendo uma baseada nas classificações das operações de crédito feitas por bancos e cooperativas, e outra definida como o índice de Basileia dessas instituições.

A partir dessas informações estimamos um modelo dinâmico com dados em painel. Os resultados obtidos não revelaram evidências de que o DPGE criou um problema de risco moral nos bancos de menor porte no Brasil.

28 Sobre essa faculdade, ver Resoluções $\mathrm{CMN}^{\circ}$ 3.464, de 26 de junho de 2007, e no 3.721, de 30 de abril de 2009, que dispõem sobre as estruturas de gerenciamento dos riscos de mercado e crédito que as instituições financeiras devem ter.

29 Com disposições dadas pela Resolução CMN n².844, de 29 de junho de 2001. 


\section{REFERÊNCIAS}

Arellano, M.; Bond, S. (1991)“Some tests of specification for panel data: Monte Carlo evidence and an application to employment equations." Review of Economic Studies, v. 58, n. 2, pp. 277-97.

Angkinand, A.; Wihlborg, C. (2010) "Deposit insurance coverage, ownership, and banks' risk-taking in emerging markets". Journal of International Money and Finance, n. 29, pp. 252-74.

Bank of International Settlements - BIS (1988) Basel Committee on Banking Supervision. International convergence of capital measurement and capital standards. Basileia, 26p.

.(2000) Basel Committee on Banking Supervision (BCBS). Principles for the management of credit risk. Basileia, 30p.

Barth, J. R.; Caprino Jr., G.; Levine, R. (2004) "Bank regulation and supervision: what works best?" Journal of Financial Intermediation, n. 13, pp. 205-48,.

Boyd, J. H.; Chang, C.; Smith, B. D. "Deposit insurance: a reconsideration." Journal of Monetary Economics, v. 49, 1235-60, 2002.

BRASIL, Banco Central do Brasil (2009) Relatório Economia Bancária e Crédito, Brasília, 168 p.

BRASIL, Banco Central do Brasil (2010a) Relatório de Estabilidade Financeira, v. 9, n. 1, Brasília, 91 p.

BRASIL, Banco Central do Brasil (2010a) Relatório de Estabilidade Financeira, v. 9, n. 2, Brasília, 62 p.

Bressan, Valéria G. F.; Braga, Marcelo J.; Bressan, Aureliano A.; Resende-Filho, Moisés A (2012) "O seguro depósito induz ao risco moral nas cooperativas de crédito brasileiras? Um estudo com dados em painel." Revista Brasileira de Economia, v. 66, n. 2, pp. 167-85.

Brewer, E.; Mondschean, T. H. (1994) "An empirical test of the incentive effects of deposit insurance: the case of junk bonds at savings and loan associations." Journal of Money, Credit and Banking, v. 26, n. 1, pp. 146-64.

Buser, S. A.; Chen, A. H.; Kane, E. J.(1981) "Federal deposit insurance, regulatory policy, and optimal bank capital'. Journal of Finance, v. 35, n. 1, pp. 51-60.

Chan, Y.; Greenbaum, S. I.; Thakor, A. V.(1992) "Is fairly priced deposit insurance possible?' Journal of Finance, v. 47, n. 1, pp. 227-45.

Demirgüç-Kunt, A.; Huizinga, H. (2004) "Market discipline and deposit insurance". Journal of Monetary Economics, n. 51, pp. 375-99. 
Freeman, S. (1988) "Banking as the provision of liquidity". Journal of Business, v.61, pp.45-64.

Gropp, R.; Vesala, J. (2004) "Deposit insurance, moral hazard and market monitoring". Review of Finance, n. 8, pp. 571-602.

Grossman, R. S. (1992) "Deposit insurance, regulation, and moral hazard in the thrift industry: evidence from the 1930's". American Economic Review, v. 82 , n. 4, pp. 800-21.

Karels, G. V.; Mcclatchey, C. A. (1999) "Deposit insurance and risk-taking behavior in the credit union industry." Journal of Banking and Finance, 23, pp. 105-34.

Keeley, M. C. (1990) "Deposit insurance, risk, and market power in banking." American Economic Review, v. 80, n. 5, pp. 1183-1200.

Marcus, A. J. (1984) "Deregulation and bank financial policy." Journal of Banking and Finance, v. 8, pp. 557-65.

Mcculloch, J. H. (1986) "Bank regulation and deposit insurance". Journal of Business, v. 59, n. 1, pp. 79-85

Merton, R. C. (1977) "An analytic derivation of the cost of deposit insurance and Ioan guarantees: an application of modern option pricing theory." Journal of Banking and Finance, v. 1, pp. 3-11.

Mesquita, M.; Torós, M. (2010) “Gestão Do Banco Central No Pânico De 2008” In: Garcia, Márcio G.P.; Giambiagi, Fábio. Risco e Regulação, Capítulo 13, Rio de Janeiro: Elsevier.

Nier, E.; Baumann, U. (2006) "Market discipline, disclosure and moral hazard in banking". Journal of Financial Intermediation, n. 15 pp. 332-61.

Oliveira, R. F.; Schiozer, R. F.; Barros, L. A. B. (2011) "Too big to fail perception by depositors: an empirical investigation."Banco Central do Brasil, Working Paper n. 233, disponível em < http://www.bcb.gov.br/pec/wps/ingl/wps233. pdf (acesso em 20/10/2012).

Pinheiro, M. A.H.P. (2008) Cooperativas de Crédito: História da Evolução Normativa no Brasil, 6 ed. Brasília: Banco Central do Brasil.

Santomero, A. M.; Vinso, J. D. (1977) "Estimating the probability of failure for commercial banks and the banking system." Journal of Banking and Finance, v. 1, pp. 185-205.

Tabak, B. M.; Gomes, G. M.R.; Medeiros Jr., M. da S. (2012) "The impact of market power at bank level in risk-taking: the Brazilian case." Working Paper Banco Central do Brasil, n. 283. 
Toledo, M. G. C. (2010) “Avaliação Da Crise: O Sistema Está Sólido”, In: Garcia, Márcio G.P.; Giambiagi, Fábio. Risco e Regulação, Capítulo 15, Rio de Janeiro: Elsevier. Windmeijer , F. (2005) "A finite sample correction for the variance of linear efficient two-step GMM estimators." Journal of Econometrics, n. 126, pp. 25-51. 